\title{
NSC-induced D-neurons are decreased in striatum of schizophrenia: Possible cause of mesolimbic dopamine hyperactivity
}

\author{
Keiko Ikemoto ${ }^{1,2}$ \\ ${ }^{1}$ Department of Neuropsychiatry, Fukushima Medical University, School of Medicine, Fukushima, Japan; ikemoto@fmu.ac.jp \\ ${ }^{2}$ Department of Psychiatry, Iwaki Kyoritsu General Hospital, Iwaki, Japan
}

Received 11 February 2012; revised 15 March 2012; accepted 17 April 2012

\section{ABSTRACT}

Neural stem cell (NSC) hypofunction is an etiological hypothesis of schizophrenia. Although dopamine (DA) dysfunction is also a widely accepted hypothesis, molecular background of mesolimbic DA hyperactivity has not yet been well known. Here, the author proposes "D-cell hypothesis", accounting for molecular basis of mesolimbic DA hyperactivity of schizophrenia, by NSC hypofunction and decrease of putative NSC-induced D-cells. The "D-cell" is defined as "non-monoaminergic aromatic L-amino acid decarboxylase (AADC)-containing cell". D-cells produce trace amines, and also take up amine precursors and convert them to amines by decarboxylation. The author reported "dopa-decarboxylating neurons specific to the human striatum", that is, "D-neurons" in the human striatum, and decrease of striatal D-neurons in patients with schizophrenia. Trace amine-associated receptor, type 1 (TAAR1), a subtype of trace amine receptors, having a quite number of ligands such as tyramine, $\beta$ - phenylethylamine (PEA) and methamphetamine, has modulating functions on monoamine neurons. It has been known that reduced binding of ligands to TAAR1 receptors on DA terminal of DA neurons of the midbrain ventral tegmental area (VTA) increased firing frequency of VTA DA neurons. In brains of schizophrenia, NSC hypofunction in the subventricular zone of lateral ventricle may cause decrease of D-neurons in the striatum and nucleus accumbens, and may result in decrease of trace amine signals. Decrease of trace amine signals to TAAR1 on VTA DA neurons may increase firing frequency of VTA DA neurons, and may finally cause mesolimbic DA hyperactivity. Increased stimulation to DA D2 receptors of NSCs might suppress NSC proliferation, and may in- duce additional mesolimbic DA hyperactivity as well as D-cell decrease. This novel theory, "Dcell hypothesis", possibly explains mesolimbic DA hyperactivity in pathogenesis of schizophrenia.

Keywords: Dopamine; D-Neuron; Ventral Tegmental Area; Schizophrenia; TAAR1

\section{INTRODUCTION}

Dopamine (DA) dysfunction [1,2], glutamate dysfunction [3,4], or neurodevelopmental deficits [5-8] are widely accepted hypotheses for etiology of schizophrenia. Nevertheless, molecular mechanism of mesolimbic DA hyperactivity $[1,2]$ as DA dysfunction has not yet been well known. In the present review, the author proposes "Dcell hypothesis", for explaining mesolimbic DA hyperactivity of schizophrenia, in which neural stem cell (NSC) dysfunction, and decrease of putative NSC-induced Dcells [9] in the striatum and nucleus accumbens [10] are involved.

\subsection{Is "D-Cell" NSC-Like Cell?}

The "D-cell" was described, by Jaeger et al. [11] in 1983 , in the rat central nervous system, and was defined "non-monoaminergic aromatic L-amino acid decarboxylase (AADC)-containing cells” [11]. D-cells produce trace amines [12,13], and may also act as an APUD (amine precursor uptake and decarboxylation) system that takes up amine precursors and converts them to amines by decarboxylation [14]. The localizations of D-cells were specified into 14 groups, from D1 (the spinal cord) to D14 (the bed nucleus of stria terminalis), in caudo-rostral orders of the rat central nervous system, using AADC immunohistochemistry $[15,16]$. In this usage of classification term, “D” meant decarboxylation. In rodents [14, $17,18]$, a small number of D-cells were described in the striatum, rostral to D14, and confirmed to be neurons by 
electro-microscopic observation [14].

The author reported in 1997, “dopa-decarboxylating neurons specific to the human striatum [19-22]”, that is, "D-neurons" in the human striatum [21,23] (classified to be D15) [21], and later in 2003, the decrease of D-neurons in the striatum and nucleus accumbens of patients with schizophrenia [10,23]. The decrease of D-neurons must be caused by NSC hypofunction in the subventricular zone of lateral ventricle.

Whereas, it is known that the number of striatal D-neurons increased in parkinsonian model rats with unilateral $6 \mathrm{OH}-\mathrm{DA}$ lesion in the substantia nigra, and the D-neurons synthesized DA after administration of L-dopa [18].

\subsection{Trace Amine-Associated Receptor, Type 1 (TAAR1) Modulates DA Function}

Since the cloning of trace amine receptors in 2001 [24,25], enormous efforts have been made for exploring signal transduction of these G-protein coupled receptors located on chromosome focus 6q23.1 [26]. The receptors have been shown to co-localize with dopamine or adrenaline transporters in monoamine neurons, and to modulate the functions of monoamines [27-29].

The trace amine-receptor, type 1 (TAAR1) has been shown to have a quite number of ligands, including tyramine, $\beta$-phenylethylamine (PEA), octopamine, and psychostimulants, for example, methamphetamine, 3,4methylenedioxymethamphetamine (MDMA) and lysergic acid diethylamide (LSD) [24,26,30], and is now a target receptor for exploring novel neuroleptics [31,32].

TAAR1 knockout mice displayed schizophrenia-like behaviors, with a deficit in prepulse inhibition [33]. TAAR1 knockout mice showed greater locomotor response to amphetamine and released more DA (and noradrenaline) in response to amphetamine than wild type mice [33].

It has been clarified that signal increase to TAAR1 receptors on cell membranes of DA neurons in the midbrain ventral tegmental area (VTA) reduces firing frequency of VTA DA neurons [26,31,33].

\subsection{D-Cell Hypothesis of Schizophrenia}

In Figure 1, "D-cell hypothesis", the novel theory for mesolimbic DA hyperactivity in pathogenesis of schizophrenia is outlined. In brains of patients with schizophrenia, NSC hypofunction in the subventricular zone of lateral ventricle [34-36] may induce reduction of Dneurons in the striatum and nucleus accumbens [10], and may result in decrease of trace amines. For example, the ventricular enlargement, noticed in brain imaging studies of schizophrenia, may be caused by NSC hypofunction of the subventricular zone of lateral ventricle [35,36].

The reduction of simulation to TAAR1 on VTA DA neurons may increase firing frequency of VTA DA neurons [31,32], and may cause mesolimbic DA hyperactivity.

DA hyperactivity in the striatum [1,2] might inhibit forebrain NSC proliferation by increasing the stimulation to DA D2 receptors [37], and may lead additional decrease of striatal D-neurons, which may induce additional hyperactivity of mesolimbic DA system.

\section{Conclusion}

Putative NSC-induced D-cells in the striatum, as trace amine producer, are clue to molecular basis of mesolimbic DA hyperactivity of schizophrenia. Further exploration of signal transduction of D-cells is essential.

“D-cell hypothesis" of schizophrenia

NSC hypofunction of subventricular zone of lateral ventricle

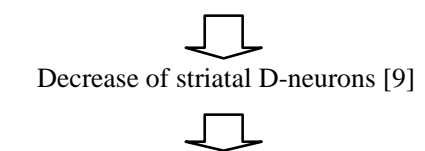

Decrease of trace amines

(striatum)

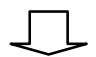

Increase of firing frequency of VTA DA neurons via TAAR1 [30,31]

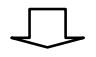

Mesolimbic DA hyperactivity
Suppression of NSC function via D2 stimulation [37]

Figure 1. "D-cell hypothesis” of schizophrenia. 


\section{ACKNOWLEDGEMENTS}

The present study was supported by Grant-in-Aid for Scientific Research from Japan Society for the Promotion of Science (JSPS) (C22591265).

\section{REFERENCES}

[1] Hokfelt, T., Ljungdahl, A., Fuxe, K. and Takashima, N. (1974) Dopamine nerve terminals in the rat limbic cortex: Aspects of the dopamine hypothesis of schizophrenia. Science, 184, 177-179. doi:10.1126/science.184.4133.177

[2] Toru, M., Nishikawa, T., Mataga, N. and Takashima, M. (1982) Dopamine metabolism increases in post-mortem schizophrenic basal ganglia. Journal of Neural Transmission, 54, 181-191. doi:10.1007/BF01254928

[3] Watis, L., Chen, S.H., Chua, H.C., Chong, S.A. and Sim, K. (2008) Glutamatergic abnormalities of the thalamus in schizophrenia: A systematic review. Journal of Neural Transmission, 115, 493-511. doi:10.1007/s00702-007-0859-5

[4] Olbrich, H.M., Valerius, G., Rüsch, N., Buchert, M., Thiel, T., Hennig, J., Ebert, D. and Van Elst, L.T. (2008) Frontolimbic glutamate alterations in first episode schizophrenia: Evidence from a magnetic resonance spectroscopy study. World Journal of Biological Psychiatry, 9, 59-63.

[5] Christison, G.W., Casanova, M.F., Weinberger, D.R., Rawlings, R. and Kleinman, J.E. (1989) A quantitative investigation of hippocampal pyramidal cell size, shape, and variability of orientation in schizophrenia. Archives of General Psychiatry, 46, 1027-1032.

[6] Duan, X., Chang, J.H., Ge, S., Faulkner, R.L., Kim, J.Y., Kitabatake, Y., Liu, X.B., Yang, C.H., Jordan, J.D., Ma, D.K., Liu, C.Y., Ganesan, S., Cheng, H.J., Ming, G.L., Lu, B. and Song, H. (2007) Disrupted-in-Schizophrenia 1 regulates integration of newly generated neurons in the adult brain. Cell, 130, 1146-1158. doi:10.1016/j.cell.2007.07.010

[7] Raedler, T.J., Knable, M.B. and Weinberger, D.R. (1998) Schizophrenia as a developmental disorder of the cerebral cortex. Current Opinion in Neurobiology, 8, 157-161. doi:10.1016/S0959-4388(98)80019-6

[8] McGlashan, T.H. and Hoffman, R.E. (2000) Schizophrenia as a disorder of developmentally reduced synaptic connectivity. Archives of General Psychiatry, 57, 637-648.

[9] Ikemoto, K. (2008) Striatal D-neurons: In new viewpoints for neuropsychiatric research using post-mortem brains. Fukushima Journal of Medical Science, 54, 1-3.

[10] Ikemoto, K., Nishimura, A., Oda, T., Nagatsu, I. and Nishi, K. (2003) Number of striatal D-neurons is reduced in autopsy brains of schizophrenics. Legal Medicine, 5, 221224.doi:10.1016/S1344-6223(02)00117-7

[11] Jaeger, C.B.,Teitelman, G., Joh, T.H., Albert, V.R., Park, D.H. and Reis, D.J. (1983) Some neurons of the rat central nervous system contain aromatic-L-amino-acid decarboxylase but not monoamines. Science, 219, 1233-1235. doi:10.1126/science.6131537

[12] Boulton, A.A. (1974) Amines and theories in psychiatry.
The Lancet, 304, 52-53.

doi:10.1016/S0140-6736(74)91390-7

[13] Boulton, A.A. and Juorio, A.V. (1979) The tyramines: Are they involved in the psychoses? Biological psychiatry, 14, 413-419.

[14] Komori, K., Fujii, T., Karasawa,N.,Yamada, K., Sakai, M. and Nagatsu, I. (1991) Some neurons of the mouse cortex and caudo-putamen contain aromatic L-amino acid decarboxylase but monoamines. Acta Histochemica et $\mathrm{Cy}$ tochemica, 24, 571-577. doi:10.1267/ahc.24.571

[15] Jaeger, C.B., Ruggiero, D.A., Albert, V. R., Joh, T.H. and Reis, D.J. (1984) Immunocytochemical localization of aromatic L-amino acid decarboxylase, In: Björklund, A. and Hökfelt, T., Eds., Handbook of Chemical Neuroanatomy. Vol. 2: Classical Transmitters in the CNS, Part I, Elsevier, Amsterdam, 387-408.

[16] Jaeger, C.B., Ruggiero, D.A., Albert, V.R., Park, D.H., Joh, T.H. and Reis, D.J. (1984) Aromatic L-amino acid decarboxylase in the rat brain: Immunocytochemical localization in neurons of the rat brain stem. Neuroscience, 11, 691-713. doi:10.1016/0306-4522(84)90053-8

[17] Tashiro, Y., Kaneko, T., Sugimoto, T., Nagatsu, I., Kikuchi, H. and Mizuno, N. (1989) Striatal neurons with aromatic L-amino acid decarboxylase-like immunoreactivity in the rat. Neuroscience Letters, 100, 29-34. doi:10.1016/0304-3940(89)90655-1

[18] Mura, A., Linder, J.C., Young, S.J. and Groves, P.M. (2000) Striatal cells containing aromatic L-amino acid decarboxylase: An immunohistochemical comparison with other classes of striatal neurons. Neuroscience, 98, 501511. doi:10.1016/S0306-4522(00)00154-8

[19] Ikemoto, K., Kitahama, K., Jouvet, A., Arai, R., Nishimura, A., Nishi, K. and Nagatsu, I. (1997) Demonstration of L-dopa decarboxylating neurons specific to human striatum. Neuroscience Letters, 232, 111-114. doi:10.1016/S0304-3940(97)00587-9

[20] Ikemoto, K., Kitahama, K., Jouvet, A., Nishimura, A., Nishi, K., Maeda, T. and Arai, R. (1998) A dopaminesynthesizing cell group demonstrated in the human basal forebrain by dual labeling immunohistochemical technique of tyrosine hydroxylase and aromatic L-amino acid decarboxylase. Neuroscience Letters, 243, 129-132. doi:10.1016/S0304-3940(98)00103-7

[21] Kitahama, K., Ikemoto, K., Jouvet, A., Nagatsu, I., Sakamoto, N. and Pearson, J. (1998) Aromatic L-amino acid decarboxylase and tyrosine hydroxylase immunohistochemistry in the adult human hypothalamus. Journal of Chemical Neuroanatomy, 16, 43-55. doi:10.1016/S0891-0618(98)00060-X

[22] Kitahama, K., Ikemoto, K., Jouvet, A., Araneda, S., Nagatsu, I., Raynaud, B., Nishimura, A., Nishi, K. and Niwa, S. (2009) Aromatic L-amino acid decarboxylase-immunoreactive structures in human midbrain, pons, and medulla. Journal of Chemical Neuroanatomy, 38, 130-140. doi:10.1016/j.jchemneu.2009.06.010

[23] Ikemoto, K. (2004) Significance of human striatal D-neurons: Implications in neuropsychiatric functions. Progress in Neuro-Psychopharmacology and Biological Psychiatry, 28, 429-434. doi:10.1016/j.pnpbp.2003.11.017 
[24] Bunzow, J.R., Sonders, M.S., Arttamangkul, S., Harrison, L.M., Zhang, G., Quigley, D.I., Darland, T., Suchland, K.L., Pasumamula, S., Kennedy, J.L., Olson, S.B., Magenis, R.E., Amara, S.G. and Grandy, D.K. (2001) Amphetamine, 3,4-methylenedioxymethamphetamine, lysergic acid diethylamide, and metabolites of the catecholamine neurotransmitters are agonists of a rat trace amine receptor. Molecular Pharmacology, 60, 1181-1188.

[25] Borowsky,.B, Adham,.N, Jones, K.A., Raddatz, R., Artymyshyn, R., Ogozalek, K.L., Durkin, M.M., Lakhlani, P.P., Bonini, J.A., Pathirana, S., Boyle, N., Pu, X., Kouranova, E., Lichtblau, H., Ochoa, F.Y., Branchek, T.A. and Gerald, C. (2001) Trace amines: Identification of a family of mammalian G protein-coupled receptors. Proceedings of the National Academy of Sciences of USA, 98, 8966-8971. doi:10.1073/pnas.151105198

[26] Miller, G.M. (2011) The emerging role of trace amineassociated receptor 1 in the functional regulation of monoamine transporters and dopaminergic activity. Journal of Neurochemistry, 116, 164-176. doi:10.1111/j.1471-4159.2010.07109.x

[27] Xie, Z. and Miller, G.M. (2007) Trace amine-associated receptor 1 is a modulator of the dopamine transporter. Journal of Pharmacology and Experimental Therapeutics, 321, 128-136. doi:10.1124/jpet.106.117382

[28] Xie, Z. and Miller, G.M. (2009) Trace amine-associated receptor 1 as a monoaminergic modulator in brain. Biochemical Pharmacology, 78, 1095-1104. doi:10.1016/j.bcp.2009.05.031

[29] Lindemann, L., Meyer, C.A., Jeanneau, K., Bradaia, A., Ozmen, L., Bluethmann, H., Bettler, B., Wettstein, J.G., Borroni, E., Moreau, J.L. and Hoener, M.C. (2008) Trace amine-associated receptor 1 modulates dopaminergic activity. Journal of Pharmacology and Experimental Therapeutics, 324, 948-956. doi:10.1124/jpet.107.132647

[30] Zucchi, R., Chiellini, G., Scanlan, T.S. and Grandy, D.K. (2006) Trace amine-associated receptors and their ligands. British Journal of Pharmacology, 149, 967-978. doi:10.1038/sj.bjp.0706948

[31] Bradaia, A., Trube, G., Stalder, H., Norcross, R.D., Ozmen, L., Wettstein, J.G., Pinard, A., Buchy, D., Gassmann, M., Hoener, M.C. and Bettler, B. (2009) The selective antagonist EPPTB reveals TAAR1-mediated regulatory mechanisms in dopaminergic neurons of the mesolimbic system. Proceedings of the National Academy of Sciences of USA, 106, 20081-20086. doi:10.1073/pnas.0906522106

[32] Revel, F.G., Moreau, J.L., Gainetdinov, R.R., Bradaia, A., Sotnikova, T.D., Mory, R., Durkin, S., Zbinden, K.G., Norcross, R., Meyer, C.A., Metzler, V., Chaboz, S., Ozmen, L., Trube, G., Pouzet, B., Bettler, B., Caron, M.G., Wettstein, J.G. and Hoener, M.C. (2011) TAAR1 activation modulates monoaminergic neurotransmission, preventing hyperdopaminergic and hypoglutamatergic activity. Proceedings of the National Academy of Sciences of USA, 108, 8485-8490. doi:10.1073/pnas.1103029108

[33] Wolinsky, T.D., Swanson, C.J., Smith, K.E., Zhong, H., Borowsky, B., Seeman, P., Branchek, T. and Gerald, C.P. (2007) The Trace Amine 1 receptor knockout mouse: An animal model with relevance to schizophrenia. Genes, Brain and Behavior, 6, 628-639. doi:10.1111/j.1601-183X.2006.00292.x

[34] Reif, A., Fritzen, S., Finger, M., Strobel, A., Lauer, M., Schmitt, A. and Lesch, K.P. (2006) Neural stem cell proliferation is decreased in schizophrenia, but not in depression. Molecular Psychiatry, 11, 514-522. doi:10.1038/sj.mp.4001791

[35] Degreef, G., Ashtari, M., Bogerts, B., Bilder, R.M., Jody, D.N., Alvir, J.M. and Lieberman, J.A. (1992) Volumes of ventricular system subdivisions measured from magnetic resonance images in first-episode schizophrenic patients. Archives of General Psychiatry, 49, 531-537.

[36] Horga, G., Bernacer, J., Dusi, N., Entis, J., Chu, K., Hazlett, E.A., Haznedar, M.M., Kemether, E., Byne, W. and Buchsbaum, M.S. (2011) Correlations between ventricular enlargement and gray and white matter volumes of cortex, thalamus, striatum, and internal capsule in schizophrenia. European Archives of Psychiatry and Clinical Neuroscience, 261, 467-476. doi:10.1007/s00406-011-0202-X

[37] Kippin, T.E., Kapur, S. and van der Kooy, D. (2005) Dopamine specifically inhibits forebrain neural stem cellproliferation, suggesting a novel effect of antipsychotic drugs. The Journal of Neuroscience, 25, 5815-5023. doi:10.1523/JNEUROSCI.1120-05.2005 